\title{
Foreword: The Three Rs of Reform Amartya Sen
}

The basic issue underlying any reform is simple enough. Some existing arrangements appear to us to be not right, and we want to put them right. When dealing with public institutions or policies, the central question, then, must be: How can we improve the institutions and policies which exist and make sure that they work better?

If there is a foundational issue to address here, it surely is the elementary fact that we cannot understand the requirements of reform without sorting out what social objectives and values should be promoted by public policy. It would be a great mistake to take reform to be some means-centered, goalindependent institutional requirement which 'must be' pursued (like the imperative to privatize or to balance the budget or to make users pay for the social services they receive) without asking any questions about how that institutional demand would influence the lives of the people involved. There may or may not be any payment-free lunch, but it would certainly be extremely odd to pursue ethics-free reform.

Let me illustrate the point by addressing a question which has been put to me by my friend, Lyn Squire, the president of the Global Development Network: 'What three factors would concern you most if you were charged with the task of initiating and implementing a major reform?' Let me start by trying to answer this question with telegraphic brevity. The three factors I would emphasize are: reach, range and reason - or more elaborately: (1) the reach of the results to be achieved, (2) the range of the ways and means to be used and (3) the reason for choosing the priorities we pursue. Let me elaborate the 'three Rs' one by one.

\section{REACH: PERSON-CENTERED, EVENHANDED}

Since there is no ethics-free reform, a central question to be addressed is: What kind of ethics should we have? Given the objectives of development, it is easy to see that the ethics involved must be person-centered as well as evenhanded. 
It has to be 'person-centered' in the sense that it must not be divorced from the lives which people can lead and the real freedoms which they can enjoy. Development cannot be seen merely in terms of the enhancement of inanimate objects of convenience, such as merely raising the GNP (or even personal incomes). High economic growth would, of course, tend to be valuable - often crucially important - accomplishments. But its value must depend on what the size, composition and nature of that growth do to the lives and freedoms of the people involved. So the basic issue is not so much whether we end up having a high rate of economic growth (important as it undoubtedly is through its causal connections), but what that growth - along with everything else happening in the economy - does for the people involved.

Further, the assessment has to be evenhanded, in the sense that it must not overlook the interests and freedoms of any group of people, particularly of those who are disadvantaged and downtrodden. The question which has to be persistently asked, while planning and implementing an economic reform, is what it is doing - directly or indirectly - to those who are at the bottom of the pyramid. ${ }^{1}$

It might be thought that all this is so obvious that it barely needs to be stated. But, I fear, that is not so. Indeed, the neglect of this basic understanding can be seen across the world. Let me illustrate the need for this person-centered, evenhanded perspective with an example from the experience of China - in many ways the most successful economic reformer in the world. One of the generally agreed understandings in applied development economics is China's remarkable success in introducing and cultivating markets and in making good use of the trading opportunities of the globalizing world. China's success has indeed been spectacular, and there is a tremendous amount that countries like India can learn from the open-minded way China has moved from being imprisoned in dogmas and red tape to become the fastest growing pragmatic economy in the world with massive economic expansion each year. If China was only a little ahead of India in terms of price-adjusted GNP or GDP per capita at the time of its economic reforms in 1979, it is immensely ahead now, despite the fact that India has also grown reasonably fast, on average, over these 25 years.

But what about the quality of life, represented, for example, by life expectancy at birth? There is quite an interesting story here. When, in the late 1940s, China had its revolution and India became independent, China and India had about the same life expectancy at birth, well below 40 years. But post-revolution China, with its egalitarian politics and continued public commitment to improve health care and education (a commitment which was carried over from its days of revolutionary struggle), brought a level of dedication to radically enhance schooling and health care which the more 
moderate Indian administration could not match. To be sure, China had the largest famine in history during 1958-61 (with close to 30 million deaths), when the so-called Great Leap Forward failed miserably. But China pulled out of that crisis soon enough. Also, the Chinese health care system, extensive and free as it was, had many problems, including a lack of quality care and much inefficiency. But there was still a general entitlement for all to some basic medical attention, irrespective of the ability to pay. As a consequence by 1979, when the economic reforms were introduced, China had a lead of about 14 years over India in longevity. Chinese life expectancy then was about 68 years, compared with India's 54 years - almost 15 years less.

Then came the economic reforms of 1979, with the Chinese economy surging ahead and growing much faster than India's more modest performance. However, despite China's much faster rate of economic growth, life expectancy in India has been growing three times as fast, on average, as that in China since 1979. China's life expectancy, which is now just about 71 years, compares with India's figure of 64 years, so that the life-expectancy gap in favor of China has been halved to seven years, over the last 25 years.

Of course, note must be taken of the fact that it gets increasingly harder to expand life expectancy further as the absolute level rises, and it could be argued that perhaps China might have now reached a level where further expansion would be exceptionally difficult. But this explanation does not work, since China's life expectancy of 71 years is still very far below the figures for many countries in the world, where the numbers stretch well into the 80s. Indeed, China's longevity is lower than some parts of India.

At the time of economic reforms, the Indian state of Kerala had a life expectancy similar to China's - about 67 years. By now, however, Kerala's life expectancy, which had already reached 74 years by $1995-99$, is considerably above China's (the latest firm figure for China's life expectancy is 71 years for 2000). Even though Beijing and Shanghai, as city-provinces, outmatch the state of Kerala (with its 30 million rural and urban inhabitants), most provinces of China have life expectancy figures far lower than Kerala's.

Going further, if we look at specific points of vulnerability, the infant mortality rate in China has declined very slowly since the economic reforms, whereas it has continued to fall quite sharply in Kerala. While Kerala had roughly the same infant mortality rate as China -37 per thousand - at the time of the Chinese reforms in 1979, Kerala's present rate, ten per thousand, reached by 2002, is one-third of China's 30 per thousand (where it has stagnated over the last decade).

There is clearly some problem with the 'reach' of the benefits of economic reform in China, despite its astounding rate of economic growth. There are three distinct problems of 'reach' here, to which any scrutinizing reformer must 
pay attention. First, even within the economic field, the poverty-removing character of Chinese economic expansion was much sharper in the early postreform period than it is today. While the early reforms caused an astonishing jump in rural production and incomes, since the late 1980s the focus of growth has been much more urban, largely related to increasing global integration of China's industrial economy. It cannot, of course, be doubted that this global integration and the related expansion of urban incomes have brought a great many rewards to the Chinese people. And yet the poverty-reducing character of Chinese economic growth, while still quite firm, has relatively slackened. Furthermore, there has been a big surge in Chinese economic inequality, that is brought out by many empirical studies, including those by Ravi Kanbur and Xiaobo Zhang and by Azizur Rahman Khan and Carl Riskin. ${ }^{2}$

However, China's slow growth in life expectancy and stagnation in infant mortality are not the result only of the worsening reach of economic growth in particular. It also relates to the social and political reach of the reforms. So, the second factor to note is that along with the political change that ushered in the economic reforms came a slackened social commitment to public health care. It led, in particular, to the eschewal of free and universal health coverage which existed prior to the reforms, provided by the state or by the collectives or cooperatives, that also poured resources directly into public health care. Now individuals needed to buy private health insurance at their own cost (except in the small minority of cases where it is provided by the employer). Interestingly, this very retrograde movement in the coverage of health care received little public resistance - as it undoubtedly would have met in any multi-party democracy like India. Indeed, it is very hard to imagine that an established public facility of great value to people could be dispensed with so easily in a country where the opposition has a strong voice. The denial of that social facility certainly had a role in the slowing down of the progress of longevity in China.

Democracy also makes a direct contribution to health care by bringing social failures into public scrutiny. India's health services are quite terrible, as Jean Drèze and I discussed in some detail in our book, India: Development and Participation. ${ }^{3}$ In December 2003, I had the dubious privilege of presenting in a news interview in Kolkata the depressing findings, related to parts of east India, of the first Health Report of the Pratichi Trust. ${ }^{4}$ But the possibility of such intense criticism is, of course, also a social opportunity to make amends. Indeed, open and persistent reporting of the dreadful state of Indian health services is, ultimately, a source of India's dynamic strength.

The informational and incentive roles of democracy, working mainly through open public discussion, can be pivotally important for the reach of public policy. Even the Chinese famines of 1958-61 were directly fed by the 
absence of democratic elections and opposition parties and the nature of the censored media. But more recently, the fact that the sudden abandonment of free public health coverage and its replacement by privately purchasable insurance could be carried through with such meager discussion and debates, and with so little opposition, points to another glaring gap. There is also the comparative immunity from political criticism which Chinese health services tend to enjoy, that, too, can be linked to the lack of a multiparty system.

This limitation came sharply to attention in the context of the SARS (Severe Acute Respiratory Syndrome) epidemic in 2003. Although SARS cases first appeared in Southern China in November 2002 and caused many fatalities, information about this new deadly disease was kept strictly under a lid until April 2003. Indeed, it was only when that highly infectious disease started spreading to Hong Kong and Beijing that the news had to be released. By then the epidemic had already gone beyond the possibility of isolation and local elimination. The lack of open public discussion evidently played a critical role in the spread of the SARS epidemic. This is a small example, but the general penalty of the lack of transparency and public scrutiny can be very pervasive indeed. $^{5}$

We have to be concerned with 'reach' in all its diverse forms, including economic reach, social reach and political reach. They are individually important and jointly momentous.

\section{RANGE: INSTITUTIONAL REFORM AND POLICY CHANGE}

I come now to range - the range of the ways and means we use. Here I can free ride to some extent on what has already been discussed in the context of reach. It is not only important to remember that the ends of institutional reform and policy change have to be 'person centered' and 'evenhanded', but also to recognize that the means to pursue those ends involve a variety of institutions - not just the invoking of a few magic bullets.

Consider the admiration for China which is a characteristic of many Indian discussions and for which there are excellent reasons in general. This, by the way, is not a new phenomenon. In the seventh century, when Yi Jing, the Chinese scholar, returned to China after spending ten years in India (studying in the Buddhist university in Nalanda but also traveling widely across the country), he asked the rhetorical question (with some evident satisfaction): 'Is there anyone in any of the five parts of India who does not admire China?'

The more recent admiration for China has tended to come in India in discrete lumps. There are those who greatly admire China's post-1979 use of reformed markets at home and abroad and link the lesson to be learned 
from China to the possibility of making intelligent use of markets. And there are others who greatly admire what China did in its pre-1979 period through radically expanding health care, basic education and social infrastructure, the benefits of which came in the form of enhanced living standards and human capabilities, including economic skills.

Which group is right? I would argue that they both are right in what they assert, and rather negligent in what they respectively ignore. India needs to learn from both parts of the momentous Chinese experience. The range of instruments has to cover, on the one hand, education, health care, building of infrastructure and land reforms and, on the other, intelligent use of domestic and global markets (rather than treating globalization as some kind of gigantic 'Jaws' which would gobble up the world). And, no less importantly, the range of instruments has to go well beyond the ground covered by the two lessons taken together. There is, in particular, the important contribution of democracy and the need to strengthen further our democratic practice.

The need for a wide 'range' relates to the fact that social changes are not only diverse, they also interrelate with each other in many different ways. To consider just one illustration, women's school education tends to have the most far-reaching effects on the lives and freedoms of all - women, men and children. There is much empirical evidence that women's literacy and schooling tend to (1) enhance the quality of women's lives, (2) reduce gender disparity in family decisions, (3) help the process of economic expansion, (4) reduce child mortality, (5) reduce gender bias in the mortality of children, (6) diminish fertility rates, (7) augment the education of all children through the influence of their mothers and (8) contribute to expanding the range and effectiveness of public debates. Similar interdependences can be seen in other areas of social change.

\section{REASON: STRATEGIES, NOT SLOGANS}

I come finally to the last of my three Rs - reason. Nothing, ultimately, is as important for reformers as the constant willingness to ask why exactly they are doing what they are doing. This is easier said than done. Recommendations for reform tend to come, alas, in the form of neat little slogans: 'open up the markets', 'get rid of the 'license Raj', 'education is the way forward', 'food first, then other things', 'fight corruption before anything else can happen', and so on. There often is considerable wisdom, not to mention energizing inspiration, in each of these mottos, but they are really battle cries, rather than battle strategies. An adequate program of reforms demands much more than aphorisms and epigrams. While we must aim at reach and must understand the 
need for range, the drawing up of policy packets requires detailed reasoning rather than being guided by piercing slogans.

Consider schooling. We certainly need more schools, including more elementary schools. But the problem of basic education is not only one of having enough schools. It is also a matter - just to give some examples - of the facilities which the schools have, the way the teachers work (whether they show up regularly, engage in teaching all children with needed care - rather than only the richer kids, preferably through private tuition), whether the parents - particularly poorer ones - have a voice in the functioning of the schools, whether the schools are safe and secure enough (especially for young girls), how the related problem of child under-nourishment affects learning and how the serving of cooked mid-day meals can be efficiently used for advancing both elementary education and basic nutrition of children. We also have to see what private schools can do and what happens to families who cannot afford such schools, and whether the private schools themselves would have adequate incentives to deliver education to the underdogs of society, even with a voucher system. There are a lot of details there, but the performance of the society and of the economy would depend, to a great extent, on reasoned assessment of precisely those details. The need to reason our way through them cannot be evaded by relying on some grand slogans or general-purpose maxims.

In his famous poem, Alfred Tennyson expressed much admiration for the 'light brigade' for following the noble principle of charging ahead without reason: 'Their's not to reason why, / Their's but to do and die'. That, I fear, won't do at all for economic or social change. Good reform is the charge of the heavy brigade. The 'reason why' is altogether central to the task.

\section{NOTES}

This is a slightly amended text of a talk given in January 2004 at the inaugural meeting of the Global Development Network in New Delhi.

1. This talk was given before the Indian general elections in May 2004, in which this issue proved to be especially critical in the downfall of the ruling Indian government. The rulers had to learn the hard way that a shining bellybutton did not a 'shining India' make.

2. See Ravi Kanbur and Xiaobo Zhang, 'Fifty Years of Regional Inequality in China: A Journey through Revolution, Reform and Openness'. Paper presented at the United Nations University World Institute for Development Economics (WIDER) conference 'Spatial Inequality in Asia', 28-29 March 2003; Azizur Rahman Khan and Carl Riskin, Inequality and Poverty in China in the Age of Globalization, New York: Oxford University Press, 2001.

3. Jean Drèze and Amartya Sen, India: Development and Participation, New York: Oxford University Press, 2002.

4. I established the Pratichi Trust with the Nobel Prize money that came my way some years ago. 
5. To avoid any uncalled for smugness about the vigor of public discussion in India, I should mention that the attention paid to health care in debates and deliberations in the Indian media, although much greater than in China, is still far from adequate (see Drèze and Sen, India: Development and Participation). The special neglect of the rising epidemic of AIDS is a particular case in point. Much more can be done in India through the use of public reasoning on such issues, especially since we are unusually fortunate in having a very long argumentative tradition and in enjoying the great opportunities provided by a multiparty democracy and a comparatively free press. See Amartya Sen, The Argumentative Indian: Writings on Indian History, Culture and Identity, New York: Farrar, Straus and Giroux, 2005. 